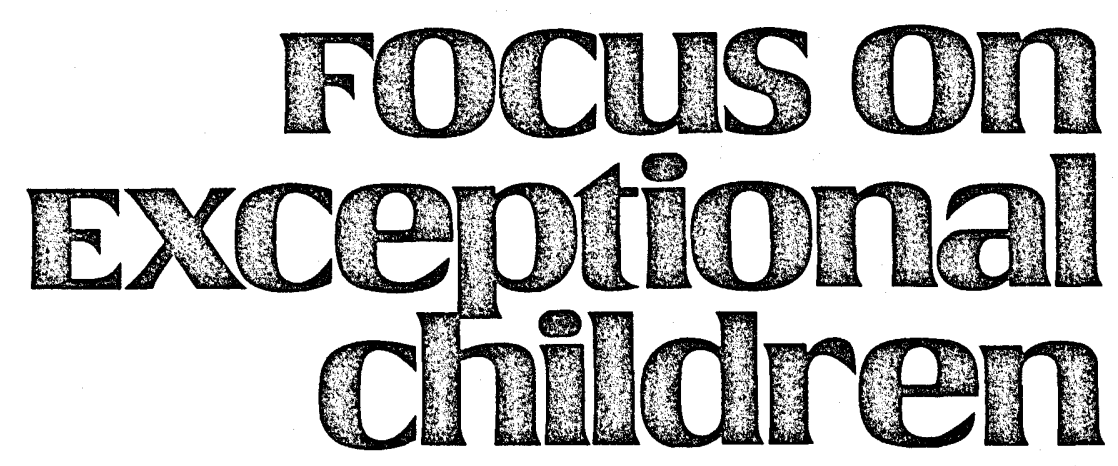

\title{
An Optimal Learning Environment For Infants and Toddlers with Severe Handicaps
}

\author{
Steven F. Warren, Cathy L. Alpert, and Ann P. Kaiser
}

Infants and toddlers with severe handicaps have immense needs. During the period when normal children develop most rapidly, the multiple deficits of children with handicaps prevent them from interacting with the environment in ways that are critical to subsequent development of motor, cognitive, communicative, and social skills. They are doubly limited by their delayed physical development and by their limited ability to engage with the environment in ways that can stimulate development. Young children with severe cerebral palsy, for example, may be so motorically impaired that they must have assistance to engage in even rudimentary self-directed exploration of the environment. Deaf-blind babies' motor, social, and communicative behaviors are limited dramatically by their lack of auditory and visual input from the environment. Many children with severe handicaps are chronically ill during early childhood (Batshaw \& Perret, 1981) and spend considerable time hospitalized. The characteristics of this particular environment, the illness itself, and the effects of the illness on mother-child interaction may further impede the child's developmental progress (Horowitz, 1982).

Current programs for infants and toddlers with severe handicaps are often inadequate (Garland, Stone, Swanson, \& Woodruff, 1981). Few teachers and support staff have appropriate and sufficient training to design and deliver the range of services this population requires. Although advances have been made in therapeutic and instructional procedures, most current techniques have been adapted from those developed for older and less handicapped children (Tjossem, 1976). The service delivery systems available for providing treatment to infants are often problematic. Home-based intervention, which has many attractive aspects, may not provide intensive enough training to promote a child's interaction with the environment. Traditionally organized early childhood intervention settings and typical therapy models may result in low rates of child-teacher contact when implemented with severely handicapped toddlers (Hart, 1982), who may require one-to-one or two-to-one child-teacher ratios (Ramey \& Trohanis, 1982). When staff-child ratios are higher, children may spend a great deal of time waiting for therapy and stimulation while the crucial period of early development slips away (Sailor \& Guess, 1983).

Steven Warren is an Associate Professor of Special Education and Psychology, Cathy Alpert a Research Assistant Professor of Special Education, and Ann Kaiser (formerly Ann Rogers-Warren) an Associate Professor of Special Education and-Psychology, all at George Peabody College for Teachers of Vanderbilt University. 
Because programs for very young children with severe handicaps have been initiated only recently, service delivery and treatment model problems are not surprising. Nevertheless, the need to design models for more effective and efficient treatment for these children is pressing (Garland et al., 1981). Simply increasing teacher-child ratios-even if such a solution were affordable-would not necessarily guarantee a higher quality of individual services. The challenges in providing quality services to handicapped children are fourfold: (a) to provide sufficient individualized training in each area of development; (b) to ensure that this training generalizes to functional contexts; (c) to promote self-directed exploration and engagement with the enviroment as a means of supplementing directly programmed training; and (d) to provide these services in a cost-effective manner. To address all of these issues, intervention programs must be designed to include specialists from several disciplines, a curriculum that is adaptable to children with a range of needs across all domains, an environment that supports child engagement and includes incidental teaching interactions to facilitate naturalistic learning, procedures to promote generalization of newly learned behaviors, and a strategy for doing all of these things with finite resources.

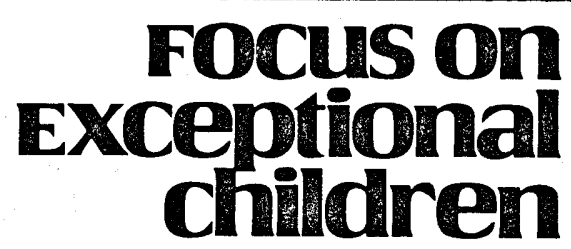

FOCUS ON EXCEPTIONAL CHILDREN (ISSNO0I5-5IIX) (USPS 203-360) is published monthly except June, July, and August as a service to teachers, special educators, curriculum specialists, administrators, and those concerned with the special education of exceptional children. This journal is abstracted and indexed in Exceptional Child Education Resources, and is also available in microform from Xerox University Microfilm. Ann Arbor, Michigan. Subscription rates, $\$ 18.00$ per year. Copyright $\odot$ 1986, Love Publishing Company. All rights reserved. Reproduction in whole or part without written permission is prohibited. Printed in the United States of America. Second class postage is paid at Denver, Colorado.

POSTMASTER: Send address changes to:

Love Publishing Company

Executive and Editorial Office

1777 South Bellaire Street

Denver, Colorado 80222

Telephone (303) 757-2579

EDITORIAL BOARD

Edward L. Meyen

University of Kansas
Glenn A. Vergason Georgia State University

Richard J. Whelan

University of Kansas Medical Center
Stanley F. Love

Publisher
Carolyn Acheson Senior Editor

\section{THE OPTIMAL LEARNING} ENVIRONMENTS MODEL

Recent developments in microcomputer technology, environmental design, and service delivery models may offer some solutions to the basic problems that face providers of infant interventions. The model presented here for the education and treatment of toddlers with severe handicaps integrates these developments. The resulting model program is based on the premise that increasing teacher-child contact and child engagement and improving the quality of instruction can be accomplished through application of the principles of environmental design and use of computer technology when applied in the framework of a transdisciplinary, consultant-therapist model. Use of an Individual Curriculum Sequencing approach in combination with other components of the model can effectively address the issues of functional use and generalization by infants and toddlers with severe handicaps. We call the resulting center-based intervention approach the Optimal Learning Environments model. We have been developing and refining this model at the John F. Kennedy Experimental School at Vanderbilt University over the past 3 years. During this time we have served over 20 children and their families. Students in the program have ranged from infants to 3 -year-olds (average age, 14 months). All children were multiply handicapped with some degree of mental retardation.

We have attempted to effectively address the individual needs of very young children with severe handicaps by designing an environment that optimizes learning opportunities within a service delivery system that minimizes logistical constraints on providing quality services. Children in the program have made substantial progress, as demonstrated by gains in tests of cognitive and motor functioning and attainment of IEP objectives in multiple areas of development.

As primary consumers of the program, parents consistently have indicated strong satisfaction with the type and quality of services provided to them and to their children. Along with the evidence on effectiveness of the model, evidence also exists on its replicability. Key components and major activities related to the model already have been systematically and effectively replicated across two early intervention programs. Further replication of the model at other sites in Tennessee and across the nation is ongoing.

\section{COMPONENTS OF THE MODEL}

Prerequisites for fully implementing the model are:

1. The classroom must be data-based.

2. The staff must be competent in basic teaching tactics (e.g., shaping, task analysis). 
3. A program must have a 1:3 staff-to-child ratio, or better.

4. The staff must be willing to try innovative approaches.

5. The staff must be committed to effective teaching as its first priority.

6. Administrative and supervisory personnel must be fully supportive.

The Optimal Learning Environments model has five basic components: environments designed for severely handicapped infants and young children, enhanced quality of instruction through technology, a transdisciplinary consultanttherapist approach, individualized curriculum sequencing, and services to families.

\section{Component 1: Environments Designed For Severely Handicapped Infants and Young Children}

Infants and toddlers with severe/multiple handicaps require intensive support and individual attention for learning and environmental interaction. When this support is not available, children are often passive, or at least not engaged in stimulating activity. During the last 10 years, guidelines for designing settings have been offered for normal infants and toddlers (Herbert-Jackson, O'Brien, Porterfield, \& Risley, 1977; O'Brien, Porterfield, Herbert-Jackson, \& Risley, 1978), moderately handicapped preschoolers (Rogers-Warren, 1982; Rogers-Warren \& Wedel, 1979), and severely handicapped adolescents (Hursh, Sayre, \& House, 1982), and adults (Kernan, Begab, \& Edgerton, 1983). The principles implicit in these guidelines have been similar and have focused on ways to increase interaction between individuals and the persons, objects, and events comprising the immediate setting. These principles, which when translated into practice increase engagement with the physical and social environments and optimize conditions for learning, are applicable to settings for very young children who have severe and multiple handicaps (Hart, 1982).

The Optimal Learning Environments model utilizes principles of environmental design to develop a setting that maximizes teacher-child and therapist-child teaching interactions, while minimizing management and custodial tasks. The classroom is divided into zones for activities, and specific staff-student arrangements are assigned to each zone throughout the day. Decisions about zones and staffing arrangements are based, in part, on research by LeLaurin and Risley (1972) indicating that dividing a classroom into zones for specific activities and assigning the staff to zones are more efficient strategies than having staff members move with individual children across areas.

Zones are designated by room dividers that are carpeted on both sides to minimize classroom noise. As recommended by Hart (1982), the dividers are high enough to prevent children from becoming visually distracted by activities in other zones but low enough to allow staff members to view the entire classroom and communicate with one another. Shelves for required training materials are located within each zone. Allowing teachers to readily find, access, and manage materials reduces non-teaching time spent searching for materials. Moreover, specifically arranging the environment so that children have access only to particular materials facilitates attention to the task.

Two other important features of the classroom include: (a) placing emphasis on programming during transitions between activities, and (b) using a modular daily schedule. To encourage children to move from activity to activity using whatever means of mobility is available to them, the classroom is designed to include unobstructed areas between zones. The classroom schedule is designed to reflect the specific programming and care needs of individual children. The modular, individualized schedule allows children with various abilities and needs to spend appropriate but different amounts of time in various activities. The "Premack Principle" (Premack, 1969) is applied to facilitate and maintain child interest and attention. In addition, generalization is programmed by scheduling a variety of adults (teachers, therapists, parents, practicum students) to work with individual children and to provide training in a variety of locales both within and outside of the classroom. A sample daily schedule is presented in Figure 1.

\section{Component 2: Enhanced Quality of Instruction Through Technology}

The second key component of the Optimal Learning Environments approach involves innovative use of microcomputer technology for enhancing the quality of instruction, as well as maximizing service delivery and teacher-child contact with severely handicapped students. Existing and emerging microcomputer technology is used in two unique applications. First, the microcomputer is used to assist teachers in IEP development, instructional decision-making, data collection and analysis, report writing, development of daily classroom schedules, and other administrative tasks. Second, the microcomputer is used to assist in direct instruction of gross motor skills.

In recent years special education teachers and researchers have demonstrated the importance of collecting data on the learning performance of students with severe handicaps (Cooper, 1981; White \& Haring, 1980). By collecting and graphing these data, teachers can determine when an instructional program is ineffective so that the program can be changed before it adversely affects the student. Until recently, however, the literature contained few specific 
January 6, 1986 (Monday)

\begin{tabular}{|c|c|c|c|c|c|c|}
\hline & CAREN & CARYN & MARK & CINDA & ELLEN & OTHEF \\
\hline $\begin{array}{l}8: 30- \\
9: 00\end{array}$ & $\begin{array}{l}\text { AREA } 2 \\
\text { Terri }\end{array}$ & $\begin{array}{l}\text { Work On } \\
\text { Computer }\end{array}$ & i & $\begin{array}{c}\text { AREA } 3 \\
\text { David \& } \\
\text { Angel } 12\end{array}$ & $\begin{array}{l}\text { BUS: } \\
\text { Jason \& } \\
\text { Alethea }\end{array}$ & i \\
\hline $\begin{array}{l}9: 00- \\
9: 15\end{array}$ & $\begin{array}{r}\text { GOOD } \\
\text { MORNING } \\
\text { GROUP }\end{array}$ & $\begin{array}{l}\text { : Work On } \\
\text { Computer }\end{array}$ & $\begin{array}{l}\text { Work On } \\
\text { Computer }\end{array}$ & PROMPTER & PROMPTER & $\vdots$ \\
\hline $\begin{array}{l}9: 15- \\
9: 45\end{array}$ & $\begin{array}{c}\text { AREA } 2 \\
\text { David and } \\
\text { Angel a }\end{array}$ & $\begin{array}{l}\text { AREA } 3 \\
\text { Alex and } \\
\text { Ale the a }\end{array}$ & $\begin{array}{l}\text { Work On } \\
\text { Computer }\end{array}$ & $\begin{array}{c}\text { AREA 1 } \\
\text { Jason \& } \\
\text { Terri }\end{array}$ & $\begin{array}{c}\text { AREA } 1 \\
\text { Assist } \\
\text { Cinda }\end{array}$ & ! \\
\hline $\begin{array}{r}9: 45- \\
10: 00\end{array}$ & i & $\begin{array}{c}\text { GO TO } \\
\text { GYM }\end{array}$ & $\begin{array}{l}\text { : Set Up } \\
\text { Snack }\end{array}$ & i & $\begin{array}{c}: \\
\vdots\end{array}$ & i \\
\hline $\begin{array}{l}10: 00- \\
10: 30\end{array}$ & $\bar{i}$ & $\begin{array}{c}\text { SNACK } \\
\text { Dauid and } \\
\text { Terri }\end{array}$ & $\begin{array}{l}\text { SNACK } \\
\text { Alex and } \\
\text { Ale thea }\end{array}$ & ! & $\begin{array}{l}\text { SNACK } \\
\text { Jason and } \\
\text { Angela }\end{array}$ & $\begin{array}{l}5 \\
\vdots\end{array}$ \\
\hline $\begin{array}{l}10: 30- \\
11: 00\end{array}$ & i & $\begin{array}{l}\text { AREA } 2 \\
\text { Ale the a }\end{array}$ & $\begin{array}{c}\text { AREA 3 } \\
\text { Jason \& } \\
\text { Alex }\end{array}$ & 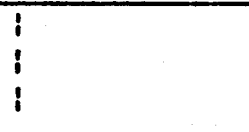 & ! & i \\
\hline $\begin{array}{l}11: 00- \\
11: 15\end{array}$ & $\begin{array}{l}\text { iBUS: } \\
\text { i PROIIPTER } \\
\vdots\end{array}$ & $\begin{array}{l}\text { MUSIC } \\
\text { GROUP }\end{array}$ & PROMPTER & ! & i & $\begin{array}{l}7 \\
\vdots\end{array}$ \\
\hline $\begin{array}{l}11: 15- \\
11: 45\end{array}$ & $\begin{array}{c}\text { AREA } 3 \\
\text { Chad \& } \\
\text { Tyree }\end{array}$ & $\begin{array}{c}\text { AREA I } \\
\text { Mark and } \\
\text { Jason }\end{array}$ & $\begin{array}{c}\text { AREA 2 } \\
\text { LaKecia \& } \\
\text { Melissa }\end{array}$ & & ! & i \\
\hline $\begin{array}{l}11: 45- \\
12: 15\end{array}$ & $\begin{array}{l}\text { iA-1: JJ/AN } \\
\text { iset Up Lunch }\end{array}$ & $\begin{array}{l}\text { AA-2: LC/MT } \\
\text { GYM/OUTSIDE }\end{array}$ & $\begin{array}{l}\text { AA-3: CS/TR } \\
\text { GYM OUTSID }\end{array}$ & & 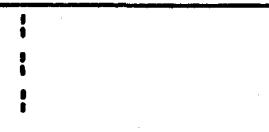 & i \\
\hline $\begin{array}{l}12: 15- \\
12: 30\end{array}$ & i & $\begin{array}{c}\text { LUNCH } \\
\text { Chad and } \\
\text { Tyree }\end{array}$ & $\begin{array}{l}\text { LUNCH } \\
\text { Jason \& } \\
\text { Mark }\end{array}$ & $\begin{array}{l}\text { LUNCH } \\
\text { iLaKecia \& } \\
\text { Melissa }\end{array}$ & ! & $\vdots$ \\
\hline $\begin{array}{l}12: 30- \\
12: 45\end{array}$ & i & $\begin{array}{l}\text { Finish } \\
\text { I Lunch and } \\
\text { Diapering }\end{array}$ & $\begin{array}{l}\text { Finish } \\
\text { Lunch and } \\
\text { Diapering }\end{array}$ & $\begin{array}{l}\text { I Finish } \\
\text { dilunch and } \\
\text { idiapering }\end{array}$ & $i$ & i \\
\hline $\begin{array}{c}12: 45- \\
1: 00\end{array}$ & i & Clean-Up & Clean-Up & Clean-Up & $\begin{array}{l}i \\
i\end{array}$ & i \\
\hline
\end{tabular}


guidelines describing exactly how to use performance data as an aid in instructional decision making.

\section{Data-Based Decision Rules}

New research has led to development of a set of guidelines, known as "data-based decision rules," that enable teachers to use performance data as a basis for instructional decision making. The effectiveness of using databased decision rules for selecting instructional strategies that result in improved rates of learning by persons with severe handicaps was reported by Haring, Liberty, and White (1980a, 1980b, 1981). Although Haring et al. (1981) found that teachers who used decision rules spent less time in planning their programs than teachers who did not, the decision rules have not been widely used. The process of using decision rules may not be practical for teachers with limited support services (Wehman, 1979), and the graphing and use of flowcharts necessary for applying data-based decision rules is perceived as a complex and time-consuming endeavor (Howell, Kaplan, \& O'Connell, 1979).

\section{AIMSTAR}

Our colleagues Hasselbring and Hamlett (1982) developed an integrated set of computer programs, titled AIMSTAR, that allows teachers to easily implement the decision-rule process in the classroom. AIMSTAR allows our teachers to develop detailed individualized education plans, manage student performance data, and implement data-based decision rules to enhance the instructional decision-making process. Graphs and monthly summary reports on student programs are produced (see Figure 2). During the first $2 \frac{1}{2}$ years of

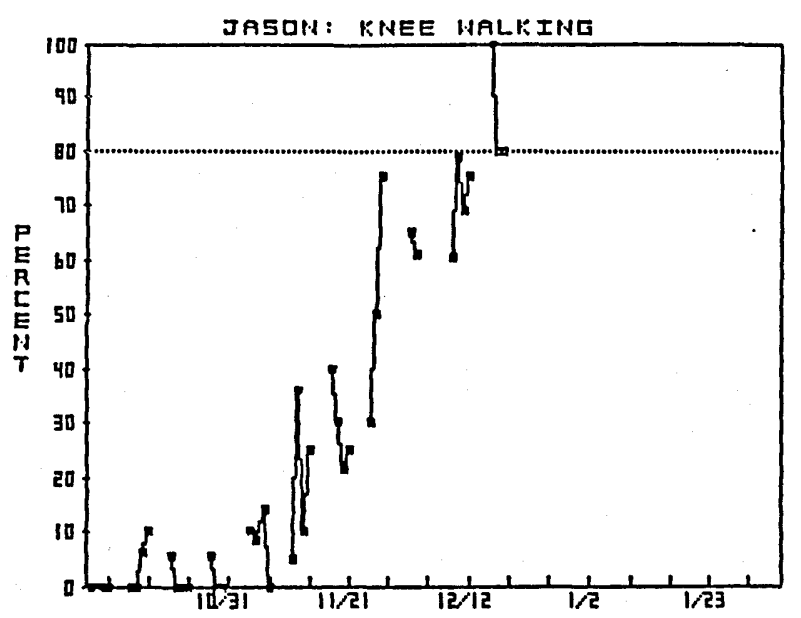

FIGURE 2

AIMSTAR Graph for ITLP Student's Knee Walking Program the model demonstration project, teachers collected data on child programs by hand and later entered the data into the AIMSTAR decision-making program. In the third year of the project, a system was developed whereby teachers entered data directly into a TRS- 80 Model 100 portable computer as they worked with students. At the end of the school day, the data were transferred electronically into the AIMSTAR program. Development of this system eliminated the time teachers previously had spent entering hand-collected data into the AIMSTAR program.

In addition to the AIMSTAR software, Hasselbring and Hamlett developed software that allows teachers to easily and efficiently design modular classroom schedules (see Component 1 ). These are individualized daily according to the adults and children present, type and length of activities, staff-student assignments, and assignment of activities and persons to zones.

\section{Direct Instruction}

Microcomputers also are used for purposes of direct instruction with children (Hooper \& Hamlett, 1985; Warren, Hooper, \& Hill, in press). Teachers construct switches that connect to the computer and a battery-operated toy. Design of the individual switches is based on a child's physical limitations and the nature of the motor or cognitive skill to be trained. Hand switches, mercury switches, and lightbeam switches have been developed to train a variety of motor skills (e.g., head erect; maintaining a hands-and-knees position; using two hands simultaneously). The computer records frequency and duration data on child responses.

In conjunction with these data, the computer also records prompt data that the trainer enters on a "touch pad." Teachers access computerized data from direct instruction in the form of trial data, summary data, and graphic presentations. The data are entered into AIMSTAR to determine when a child reaches criterion on a goal and when changes in instructional procedures are in order.*

\section{Component 3: Transdisciplinary Consultant- Therapist Approach}

To realize their developmental potential, infants and toddlers with severe and multiple handicaps require intensive intervention efforts from a variety of disciplines, as well as support from parents. The traditional model of therapy, in which a therapist provides treatment in the area of his or

\footnotetext{
*The software and hardware applications described here were developed in cooperation with Expert Systems Software, 923 Van Leer Dr., Nashville, TN.
} 
her expertise, often has been ineffective with children having the range and degree of needs of the severely handicapped (Holm \& McCartin, 1978).

\section{Traditional Specialist Approach}

Shortcomings associated with the traditional specialist approach are that: (a) the amount of time treatment is provided in a specific area is limited because only the specialist works with the child; significant others who interact with the child frequently in natural contexts (e.g., parents and teachers) do not participate in treatment within specialty areas; (b) the specialist seldom obtains detailed information from the teacher and parents concerning the child's problems or progress outside the specialist's treatment setting; (c) assessment, remediation, and evaluation typically are conducted in a single "therapeutic setting" that bears little resemblance to the child's normal environments; moreover, little thought is given to the importance of skills trained for the child's day-to-day functioning; (d) generalization of trained skills to appropriate non-training contexts often is limited bcause skills are taught by a single individual, in a very specific context, often under highly predictable circumstances; and (e) training of skills from one specialty domain is isolated from training of skills in other domains. Complex interdependencies exist between superficially distinct skills (Hayden \& McGinness, 1977) and, hence, an integrated training approach in which skills from different areas of development are trained concurrently may enhance the functionality and generalized use of trained skills by children (Guess \& Noonan, 1982).

\section{A New Model}

Empirical evidence of the ineffectiveness of the traditional specialist approach led a number of innovators in special education to propose (and in some cases demonstrate) the use of a transdisciplinary, consultant-therapist model (Hanson, 1981; Guess, Jones, \& Lyon, 1981; McCormick \& Goldman, 1979). This model is based on the transdisciplinary team approach to service delivery and the concept of "role release" (Lyon \& Lyon, 1980) by therapists, teachers, and other personnel. The consultant-therapist model differs from the specialist approach in that the specialist, teachers, and parents share responsibility for conducting planned remediation. The consultant-therapist designs the instructional program so that teachers, parents, paraprofessionals, and other therapists can implement portions of it.

The consultant-therapist also assesses the child's behavior in a range of contexts typical of the child's natural environments and obtains teacher and parental input to identify absent skills or maladaptive behaviors that limit the child's ability to function. Skills targeted for training are those that will improve the child's functioning in day-to-day activities. Generalization is facilitated because the consultanttherapist approach involves integrated skill training, training of functional skills, and training by a number of persons in a variety of meaningful contexts.

In the consultant-therapist approach, then, the specialist is involved in identification and remediation of the child's problems in one area defined as the "specialty." The specialist additionally "releases" his or her role by training teachers, parents, therapists, and paraprofessionals to provide the prescribed intervention. The specialist observes these persons as they work with children and provides feedback and additional training as needed. He or she also develops procedures for data collection and modifies individual child programs as indicated by the data.

The Optimal Learning Environments model utilizes a transdisciplinary consultant-therapist approach. A transdisciplinary team consists of special education teachers, a speech/language therapist-consultant, a physical therapistconsultant, and a parent trainer. Other specialists, such as a nutritionist and a vision specialist, may be consulted on an individual child basis. Consultant-therapists are responsible for: (a) analyzing each child's problems and educational needs in the area defined as the specialty; (b) designing individualized instructional plans to meet the needs identified; (c) training teachers, teacher aides, parents, and other therapists to implement various components of the instructional plans; (d) specifying data relevant to evaluation of the instruction; and (e) assessing the effectiveness of, and modifying accordingly, the instructional efforts and the learning environments.

A transdisciplinary team meeting is held on a weekly basis. Topics discussed include individual child needs, program plans and modifications, data collection procedures, and so on. Specialists also train classroom personnel, as necessary, during the weekly team meetings. In addition to these formal meetings, team members meet informally on a daily basis.

\section{Component 4: Individualized Curriculum Sequencing}

Two concerns influenced the selection of a curriculum approach to be implemented in this model. The first concern was in providing truly individualized training sequences that would adequately reflect the composite of needs displayed by infants and toddlers who have severe and multiple handicaps. The second concern was for teaching skills that would be immediately functional for the children. To meet these concerns, the curriculum would have to be specific, yet adaptable to a range of developmental levels across domains within the same child and across a group of children. It also 
should facilitate skill integration and generalization of newly learned skills to everyday contexts.

The Individualized Curriculum Sequencing (ICS) model (Brown, Holvoet, Guess, \& Mulligan, 1980; Holvoet, Guess, Mulligan, \& Brown, 1980; Mulligan \& Guess, 1984) is utilized in our Optimal Learning Environments approach because it addresses the concerns for functional use and integration of skills into new behavior patterns. Implementation of the ICS begins with a thorough evaluation of a child's skills in all domains (gross and fine motor; social development; communication; self-help; and cognitive) using formal and observational assessment procedures. Target skills in each domain are identified using the dual criteria of appropriateness to the developmental sequence and functionality in the child's typical environments. Individual target skills then are assigned to classroom activities and events that offer appropriate opportunities for the behaviors to be trained in a functional and natural manner.

Four or five target skills typically are assigned to an activity. These skills are sequenced or "clustered" into logical sets. Clustering is based on the functional occurrences of behavior such that one behavior or response logically leads to the next behavior in the training sequence. For example, a skill cluster may teach a child to: (a) imitate the word "up" (communication); (b) pull to stand and maintain standing (gross motor); (c) discriminate between two toys (preacademic); (d) imitate the name of the object selected (communication); and (e) manipulate the object appropriately with another child (social). This cluster approximates a natural sequence of events.

A series of clusters, each consisting of four or five related, functional, child-appropriate behaviors can be identified and presented several times across the classrom day. In this way, single skills across content areas are distributed within and across sequences so that skill integration is programmed and mass trials of the same skill rarely occur in succession. This distribution across functional contexts facilitates acquisition and programs for generalization by providing training in multiple settings with several trainers.

The ICS interfaces well with other key components of the Optimal Learning Environments model. Specifically, assignment of activities to zones, use of a modularized schedule with age-appropriate activities, involvement of a transdisciplinary team, and use of computer-managed decision making and record keeping systems form an excellent base for ICS application.

\section{Component 5: Services to Families}

The birth of a child with handicaps impacts the family system in a variety of ways. Parents must attend to the child's medical and therapeutic needs and, at the same time, deal with their own and other family members' emotional responses (Wikler, 1981). Parental needs may range from assistance with planning to meet new financial demands, to learning new skills that address the child's health, therapeutic, and educational needs. Without considerable professional help and support, parents may struggle for years to meet their basic emotional and child management needs.

From a more positive perspective, parents have a great deal to offer their children in the way of teaching. Young children normally learn far more from their mothers and fathers than from any preschool program. Most fundamental conceptual, communicative, and self-help skills are learned in the context of the home. Although this may be less true in the case of a child with severe handicaps, parents still must be recognized as a great source of teaching for their child, and incorporated into their child's education program in ways that are advantageous for the child, the parents, and the education program. Parent involvement in early education of children with severe and multiple handicaps is essential if these children are to reach their developmental potential (Linder, 1983).

The Optimal Learning Environments model includes a comprehensive range of training and support services for parents. Parent needs are assessed regularly (every 4 to 6 months) through a written needs assessment, informal observation by team members, and discussion between team members and parents. Following the identification of parent needs, an individualized family plan (IFP) is developed; it takes into account the needs and dynamics of each family situation. In developing the IFPs, efforts are made to meet the support, training, and informational needs of parents, plan for father involvement, and address the needs of nonhandicapped siblings.

Development of IFPs is based on the notion of "evolving needs" of parents of children with handicaps (Turnbull, 1984). The notion of "evolving needs" maintains that the needs of individual parents change over time and are affected by a variety of factors including the child's health and developmental status, responses to the child and family by relatives, friends, and professionals, the availability of support services, financial constraints on the family, and so on. Given the individual and fluctuating nature of parents' needs, IFPs are developed and reviewed jointly by the parent and parent trainer on a regular and frequent basis.

The model of parent involvement, then, includes identifying individual parent needs and providing a variety of training and support options to address those needs. The classroom staff does not prescribe the specific nature of each parent's involvement in the child's early intervention. Rather, the parent and parent trainer determine this jointly. Services to families that are available through the model demonstration project are described in the following paragraphs. 


\section{Classroom Participation}

All parents are involved in developing their child's individualized education program (IEP) and participating in the IEP meetings. Parents who indicate an interest, and who are not hindered by time constraints, participate in the classroom program for a few hours each week. During this time the parents observe the child's educational program, actively participate in various aspects of the training program (e.g., feeding, motor skill training, toileting), and receive instruction in procedures for teaching the child and collecting data. Some of the parents also are taught to enter their child's data into the AIMSTAR data management program.

\section{Parents Support Group Meeting}

Parents support group meetings are held every other week. These meetings provide a forum for parents to share feelings and experiences, exchange information, and learn about topics relevant to rearing a child with special needs. Parents often suggest topics for discussion, and the parent trainer organizes the meetings and makes arrangements for guest speakers, as necessary. Recent topics include estate planning (the guest speaker was a professor of law from Vanderbilt University) and preparing for the child's enrollment in public school (the guest speaker was a special education teacher from the Nashville Metro School District). Parental emotional needs also are addresssed in the parent support group meetings. When individual support or counseling needs cannot be met in this context, parents are referred to the Kennedy Center Family and Child Study Center, where individual therapy and family and marital counseling are provided.

\section{Home Visits}

Individual team members visit families at home once a month or every 2 months, depending on the nature and extent of family needs. Home visits often involve training parents how to use specific interactional, intervention, and management skills. The education and management of a young child with severe and multiple handicaps also can be facilitated in the home through application of the same principles of environmental design that are utilized in the classroom. Therefore, home visits also focus on assisting parents in the arrangment of home environments to facilitate child learning and care of the child. Emphasis is placed on lowcost, flexible arrangements that can be modified as the child's and family's needs change.

\section{Training Parents in Management and Treatment Strategies}

The parent trainer, teachers, and consultant-therapists pro- vide parents with training, as needed, in child management and treatment skills. Training is offered in behavior management, physical therapy, strategies for teaching self-help skills, and incidental language teaching procedures. Parent management and treatment skill training is provided both in the classroom and during home visits.

\section{Information and Support Services}

A variety of support networks and services is available to families with handicapped children in the Nashville area. The parent trainer provides parents with information about many of these services and facilitates contact between parents and organizations/services as desired and needed by individual families. The family component also makes available to parents a resource library containing books, articles, pamphlets, and other material on handicapping conditions, intervention procedures, programs for children with special needs, and so forth. In addition, a respite care file containing names of persons who are interested in providing temporary child care was compiled and is available to parents.

\section{EVALUATION OF THE MODEL}

The Optimal Learning Environments model integrates the five components discussed into an intensive data-based intervention program. The most basic assumption underlying this model is that child engagement with the environment is a critical characteristic of an optimal learning environment (Hart, 1982; McWilliam, Trivette, \& Dunst, 1985). Infants and toddlers with severe and multiple handicaps often are characterized by a lack of self-directed exploratory behavior. Thus, an intervention must, at the minimum, increase the child's engagement with persons and objects as a requisite condition for increasing learning and facilitating development.

\section{Pragmatic Assumptions}

In addition to this philosophical assumption, pragmatic assumptions about the characteristics of an effective program are:

1. The intervention should address the goals identified for each child during the IEP process.

2. A high percentage of the staff's time should be spent in non-caretaking activities with the children.

3. Transition time between activities should be minimal.

4. Teaching should occur in all activities during the school day. 


\section{Observation Coding}

Based on these assumptions, we designed and implemented a classroom observation code to measure: (a) the kinds of activities ongoing in the classroom; (b) teacher-child contact time in terms of occurrence and content of the interactions; (c) child engagement with materials and teachers; (d) teacher activity; (e) monitoring of child performance; and ( $f$ ) teacher-child ratios.* In addition to the information obtained from the code, IEPs were reviewed to generate a list of specific treatment goals for each child so that treatment in the classroom could be coded as goal-related or general. To determine major activity codes, observations of several infant classrooms were made.

The protocol for coding is based on a scanning system. A scan is a 35-second interval in which the observer watches and records behavior for a single subject for 30 seconds, then locates the next subject during seconds $31-35$. At the beginning of the observation, the children and teachers are assigned a sequence for scanning. This sequence is followed until each subject has been observed at least six times. Total reliability for the code averaged $88 \%$ (range $=81 \%-97 \%$ ). Careful analyses of the code showed the reliability for each category to be well above $85 \%$.

\section{Analysis of Data}

Data are presented on teacher behavior, the delivery of treatment across time and activities, and child engagement. For purposes of comparison, data related to teacher behavior and the delivery of treatment across time and activities are provided from the model demonstration project (School A), as well as from two other classrooms for infants and toddlers with severe and multiple handicaps. School B has 10 children enrolled in a full-day intervention program and follows a fairly traditional preschool schedule. School $\mathrm{C}$ is a full-day program with six children enrolled. Teacher-child ratios for the three settings are typically: School A-1:2; School B1:3; School C-1:3. Data on child engagement are provided from two time periods (with approximately 15 observations per time period) at Schools A and B.

As shown in Figure 3, the Optimal Learning Environments model (School A) clearly differed from the other two sites in terms of time devoted to treatment (treatment was defined as teaching related to specific IEP goals). Teachers in this setting devoted $65 \%$ of their observed time to training related to IEP goals, while teachers in the other two settings spent slightly less than $20 \%$ of their time in treatment. Teachers

\footnotetext{
*This observation code is available from the authors upon request, c/o Dept. of Special Education, Box 328, George Peabody College for Teachers, Vanderbilt University, Nashville, TN 37203.
}

in School A generally spent less time in non-teaching activities (passive, material, unoccupied, and other) than did teachers in the other two settings.

Teachers in School A distributed their treatment across all activities in the classroom, as shown in Figure 4. School $B$ teachers provided treatment primarily during Manipulative and Doing activities. School $\mathrm{C}$ teachers provided the most treatment during an Exercise period, when they worked on physical therapy goals.

As shown in Figure 5, analyses of treatment across time periods confirmed that teachers in School A were teaching across activities; treatment was observed during $60 \%$ to $70 \%$ of the intervals observed across the day. Teachers in School $B$ also delivered treatment throughout the day; however, the level of treatment was significantly lower than for teachers in School A, averaging less than $25 \%$ of the observed intervals. Teachers in School C provided treatment during the first 2 hours of the day, but the intensity of treatment was much higher during the first hour than during the second (50\% vs. $9 \%$ ). Since levels of treatment might vary according to teacher-child ratios, a comparison was made using a subset of data in which the same teacher-child ratio occurred in each setting. The pattern of differences was nearly identical to the one described in Figure 3, suggesting that the difference in distribution of teacher activity was not a function of number of adults in the setting.

With regard to child engagement, children at the model demonstration program were engaged with teachers or materials during $90 \%$ of the observed intervals at Time 1 and $86 \%$ of the observed intervals at Time 2. Children at School $B$ were engaged with teachers or materials during $53 \%$ of the observed intervals at Time 1 and $63 \%$ of the observed intervals at Time 2 .

Comparison of the Optimal Learning Environments model classroom with two other classrooms indicates that the model resulted in: (a) much more actual teaching time and less

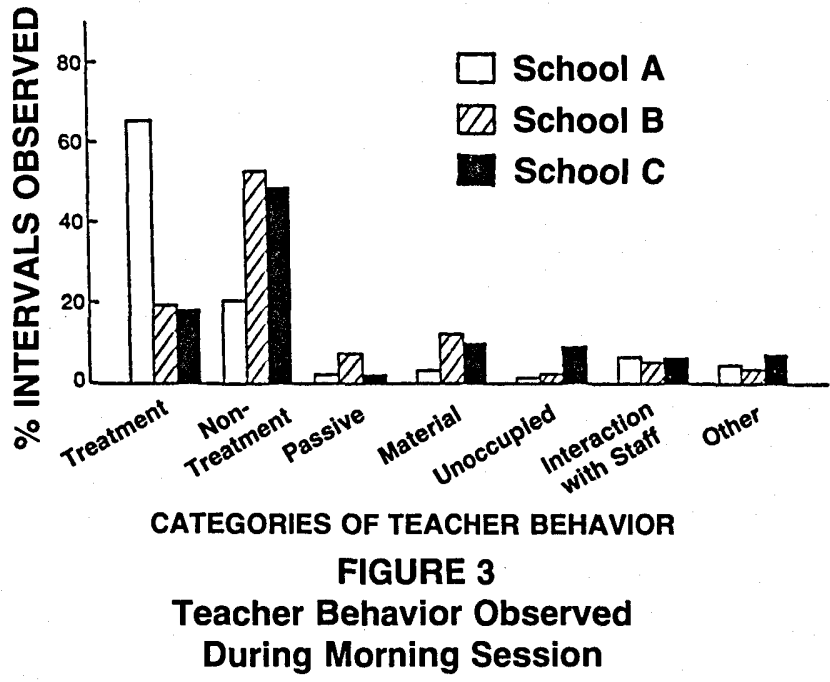




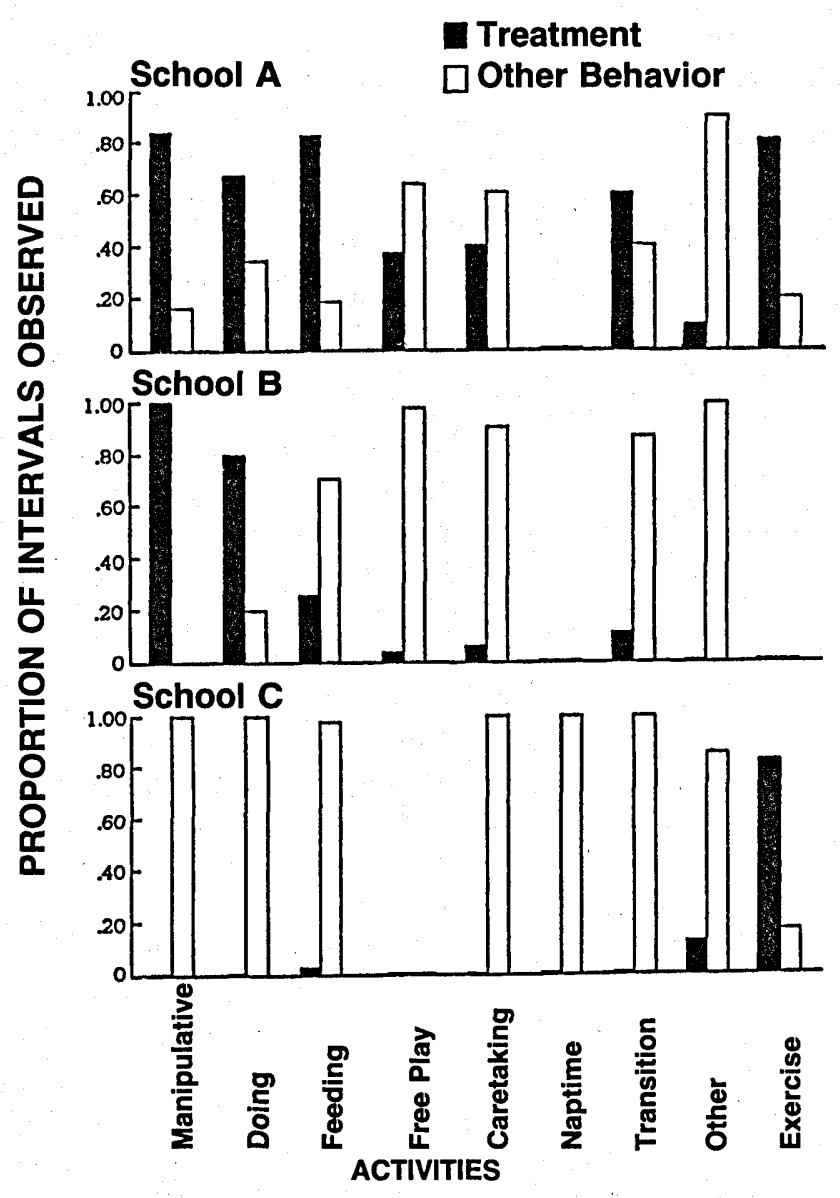

FIGURE 4

Teachers' Treatment Vs. Other Behavior Across Various Activities

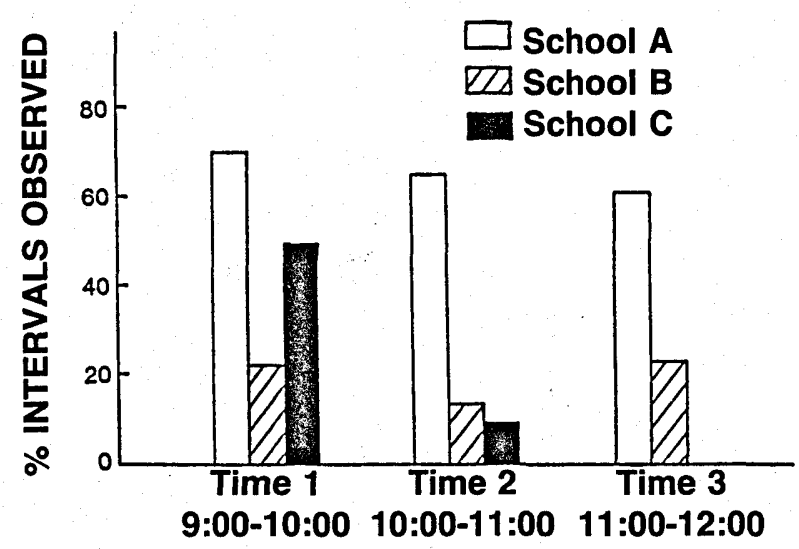

TIME PERIODS

Teachers' Treatment Behavior Across Different Times

time in non-teaching activities; (b) skills being taught across the day and across different types of activities; (c) higher levels of teaching within specific activities; and (d) higher child engagement levels. In short, the model resulted in more teaching and higher levels of child engagement. Over the long-term these two variables should facilitate optimal child outcome.

\section{CONCLUSION}

The need for effective early intervention programs to meet the needs of infants and toddlers with severe handicaps is critical. Efforts to identify children with handicaps have been successful; each year more children are screened and evaluated before the age of 3 . Nevertheless, with the increasing birthrate, the survival of more babies with severe handicaps, and the decreasing federal and state support for prenatal care, the next decade likely will see a record number of children requiring intervention in the first three years of life.

These increasing numbers of children are not likely to be matched with increasing support for very early intervention. Most states have not yet extended the mandate of PL 94-142 to the education of children between birth and 3 years (Cohen, Semmel, \& Guralnick, 1979; Linder, 1983), and downward extension appears unlikely in the next few years. Two pieces of evidence might be persuasive in encouraging states to assume responsibility for the education of very young handicapped children. The first is evidence of immediate child progress and long-term effects resulting from intervention in the first three years of life, particularly for children with moderate to severe handicaps. The second is evidence that positive results can be obtained in ways that are cost-efficient. The demonstration of an effective model for early intervention and the analysis of costs of each component of that model could contribute important information on these issues.

For educators who are interested in very young children, the immediate challenge is to develop and refine educational and service delivery strategies that fully meet the needs of this special population and their families. The requirements of intensive, multidisciplinary programming for children who have a limited range of skills are considerable. Meeting individual needs effectively and maximizing the benefits of intervention are primary concerns.

The Optimal Learning Environments model seeks to address the individual needs of very young children with severe handicaps by designing an environment that maximizes learning opportunities within a service delivery system that minimizes logistical constraints on quality services. Initial evaluation suggests that this model results in a qualitatively and quantitatively positive educational experience for young children with very severe handicaps. Long-term systematic 
replication, combined with comprehensive evaluation, is needed now to determine the true efficacy of this model.

\section{REFERENCES}

Batshaw, M. L., \& Perret, Y. M. (1981). Children with handicaps: A medical primer. Baltimore: Paul Brookes Publishing.

Brown, F., Holvoet, J., Guess, D., \& Mulligan, M. (1980). The individualized curriculum sequencing model (III): Small group instruction. Journal of the Association of the Severely Handicapped, 5, 352-367.

Cohen, S., Semmel, M. \& Guralnick, M. Public Law 94-142 and the education of preschool handicapped children. Exceptional Children, $1979,45,279-285$.

Cooper, J. O. (1981). Measuring behavior. Columbus, OH: Charles E. Merrill.

Garland, C., Swanson, J., Stone, N. W., \& Woodruff, G. (Eds.). (1981). Early intervention for children with special needs and their families. Seattle: WESTAR.

Guess, D., Jones, C., \& Lyon, S. (Eds.). (1981). Developing an intervention program for severely/multiply handicapped preschool children: A transdisciplinary approach. Unpublished manuscript, University of Kansas, Lawrence.

Guess, D., \& Noonan, M. J. (1982). Curricula and instructional procedures for severely handicapped students. Focus on Exceptional Children, 14 (5), 1-12.

Hanson, M. J. (1981). A model for early intervention with culturally diverse single and multi-parent families. Topics in Early Childhood Education, 1, 37-44.

Haring, N. G., Liberty, K. A., \& White, O. R. (1980a). Data-based decision rules for instructional programs. Unpublished monograph, University of Washington Child Development and Mental Retardation Center, Seattle.

Haring, N. G., Liberty, K. A., \& White, O. R. (1980b). Rules for databased decisions in instructional programs: Current research and instructional implications. In W. Sailor, B. Wilcox, \& L. Brown, (Eds.), Methods of instruction for severely handicapped students. Baltimore: Paul Brookes Publishing.

Haring, N. G., Liberty, K. A., \& White, O. R. (1981). An investigation of phases of learning and facilitating instructional events for the severely and profoundly retarded. Unpublished monograph, University of Washington, College of Education, Seattle.

Hart, B. (1982). So that teachers can teach: Assigning roles and responsibilities. Topics in Early Childhood Special Education, 2, 1-9.

Hasselbring, T. S., \& Hamlett, C. (1982, May). Using the microcomputer to apply data-based decision rules for assisting in the selection of instructional strategies for the handicapped. Proceedings of the Twentieth Annual Association for Education Data-Systems Conference, Orlando, FL.

Hayden, A. H., \& McGinness, G. D. (1977). Bases for early intervention. In E. Sontag (Ed.), Educational programming for the severely and profoundly handicapped. Reston, VA: Council for Exceptional Children.

Herbert-Jackson, E., O'Brien, M., Porterfield, J. \& Risley, T. (1977). The infant center: A complete guide to organizing and managing infant day care. Baltimore: University Park Press.

Holm, V. A., \& McCartin, R. E. (1978). Interdisciplinary child development team: Team issues and training in interdisciplinariness. In K. E. Allen, V. A. Holm, \& R. L. Schiefelbusch (Eds.), Early interventionA team approach. Baltimore: University Park Press.

Holvoet, J., Guess, D., Mulligan, M., \& Brown, F. (1980). The individualized curriculum sequencing model (II): A teaching strategy for severely handicapped students. Journal of the Association of the Severely Handicapped, 5, 325-336.

Hooper, E. H., \& Hamlett, C. (1985, June). Microcomputer applications for young children with severe handicaps. Paper presented at the Council for Exceptional Children National Software Conference, Alexandria, VA.
Horowitz, F. D. (1982). Infant environments. In A. Rogers-Warren (Ed.), Final Report of the Kansas Early Childhood Institute. University of Kansas, Lawrence.

Howell, K. W., Kaplan, J. S., \& O'Connell, C. Y. (1979). Evaluating exceptional children: A task analysis approach. Columbus, $\mathrm{OH}$ : Charles E. Merrill Publishing.

Hursh, D., Sayre, T., \& House, D. (1982, May). PUSH: Evaluating the design process. Paper presented at the annual meeting of the Association for Behavior Analysis, Milwaukee, WI.

Kernan, K., Begab, M., \& Edgerton, R. (Eds.). (1983). Environments and behavior: The adaptation of mentally retarded persons. Baltimore: University Park Press.

LeLaurin, K., \& Risley, T. R. (1972). The organization of day care environments: "ZONE" versus "man to man" staff assignments. Journal of Applied Behavior Analysis, 5, 225-232.

Linder, T. (1983). Early childhood special education. Baltimore: Paul Brookes Publishing.

Lyon, S., \& Lyon, G. (1980). Team functioning and staff development: A role release approach to providing integrated educational services to severely handicapped students. Journal of the Association for the Severely Handicapped, 5, 250-263.

McCormick, L., \& Goldman, R. (1979). The transdisciplinary model: Implications for service delivery and personnel preparation for the severely and profoundly handicapped. AAESPH Review, 4, 152-161.

McWilliam, R. A., Trivette, C. M., \& Dunst, C. J. (1985). Behavior engagement as a measure of the efficacy of early intervention. Analysis and Intervention in Developmental Disabilities, 5, 59-72.

Mulligan, M., \& Guess, D. (1984). Using an individualized curriculum sequencing model. In L. McCormick \& R. L. Schiefelbusch (Eds.). Early language intervention. Columbus, $\mathrm{OH}$ : Charles E. Merrill Publishing.

O'Brien, M., Porterfield, J., Herbert-Jackson, E., \& Risley, T. (1978). The Toddler Center: A practical guide to day care for one-and two-year olds. Baltimore: University Park Press.

Premack, D. (1969). Reinforcement theory. In Nebraska symposium on motivation. Lincoln: University of Nebraska Press, pp. 123-128.

Ramey, C. T., \& Trohanis, P. L. (Eds.). (1982). Finding and educating high-risk and handicapped infants. Baltimore: University Park Press.

Rogers-Warren, A. K. (1982). Behavioral ecology in classrooms for young, handicapped children. Topics in Early Childhood Special Education, 2, 21-22.

Rogers-Warren, A., \& Wedel, J. (1979). The physical ecology of preschool classrooms for the handicapped. In J. Gallagher (Ed.), New directions for exceptional children (Vol. 1). San Francisco: Jossey-Bass.

Sailor, W., \& Guess, D. (1983). Severely handicapped students-An instructional design. Boston: Houghton Mifflin.

Tjossem, T. D. (Ed.). (1976). Intervention strategies for high risk infants and young children. Baltimore: University Park Press.

Turnbull, A. (1984, November). Research in family systems. Paper presented in the Department of Special Education, Peabody College of Vanderbilt University, Nashville, TN.

Warren, S. F., Hooper, E. H., \& Hill, E. W. (in press). Some innovative educational applications of advanced technologies. In D. Guess, L. Goetz, \& K. Stremel-Campbell (Eds.), Innovative program design for individuals with sensory impairments. Baltimore: Paul Brookes Publishing.

Wehman, P. (1979). Curriculum design for the severely and profoundly handicapped. New York: Human Services Press.

White, O. R., \& Haring, N. G. (1980). Exceptional teaching (2nd ed.). Columbus, OH: Charles E. Merrill.

Wikler, L. (1981). Chronic stresses of families of mentally retarded children. Family Relations, 30, 281-288.

Support for the research and development activities discussed in this article was provided through a model demonstration grant from the Handicapped Children's Early Education Program, Special Education Programs, U.S. Department of Education (\#G008302259). The contributions of our colleagues Ted S. Hasselbring, Caren Millen, Eva Hooper, Joji Colond, Kris Derer, and Carol Hamlett are gratefully acknowledged. 


\section{Professional update}

\section{MEETING}

May 25-29, 1986

American Association on Mental

Deficiency Annual Meeting

Radisson Hotel Denver

Denver, Colorado

For information contact:

AAMD

1719 Kalorama Road, N.W.

Washington, DC 20009

(800) 424-3688

\section{NEW BOOKS}

\section{Assessing Severely and Profoundly Handicapped Individuals}

by Anthony F. Rotatori, John O. Schwenn, and Robert A. Fox

This new book draws upon a number of contributors to produce a comprehensive and practical compendium of assessment with the severely and profoundly handicapped. It includes discussion of characteristics, strategies and methods, curriculum resources, and procedures. The primary audience for the book is teachers and vocational trainers of the severely/profoundly handicapped, or as a professional reference.
The first part of this book covers theories and models and presents the AIME model as a framework. It also defines the population that is the subject of the book. Section 2 covers both the traditional assessment domains (intellectual, adaptive, language) and the nontraditional areas (motivation, initial learning behaviors) and summarizes some of the applicable assessment instruments.

This hardbound volume of 272 pages is published by Charles C Thomas, Springfield, IL.

\section{Directory of College Facilities And Services for the Disabled}

by Carol H. Thomas and James L. Thomas

This second edition of the critically acclaimed Directory provides information on more than 2,300 programs and services available for the disabled in postsecondary institutions within the United States and all Canadian provinces. This information includes demographic data, the type of institution and certification offered, and information on the physical terrain, as well as the standard information.

New features include an index to disabilities served and an updated bibliography of reading materials, as well as a resource list of associations, centers, organizations, societies, clearinghouses, data bases, and print sources. The Directory is tailored to meet the needs of disabled collegebound persons, their parents, and high school and college counselors.

The Directory is published by the Oryx Press, Phoenix, $\mathrm{AZ}$, and the toll-free number for ordering is $1-800-457$ ORYX. 